Check for updates

Cite this: Chem. Commun., 2020, 56, 13359

Received 21st August 2020,

Accepted 30th September 2020

DOI: $10.1039 / d 0 c c 05694 d$

rsc.li/chemcomm

\section{The first ring-expanded NHC-copper(I) phosphides as catalysts in the highly selective hydrophosphination of isocyanates $\dagger$}

\author{
Thomas M. Horsley Downie, (D) ${ }^{a}$ Jonathan W. Hall, ${ }^{a}$ Thomas P. Collier Finn, ${ }^{a}$ \\ David J. Liptrot, (D) ${ }^{\star a}$ John P. Lowe, (D) ${ }^{a}$ Mary F. Mahon, ${ }^{\star b}$ Claire L. McMullin (D) ${ }^{a}$ \\ and Michael K. Whittlesey (D)
}

\begin{abstract}
A range of $\mathrm{N}$-heterocyclic carbene-supported copper diphenylphosphides (NHC = IPr, 6-Dipp, SIMes and 6-Mes) were synthesised. These include the first reports of ring-expanded NHC-copper(I) phosphides. The compounds were characterised by NMR spectroscopy and X-ray crystallography. Reaction of (6-Dipp)CuPPh with isocyanates, isothiocyanates and carbon disulfide results in the insertion of the heterocumulene into the $\mathrm{Cu}-\mathrm{P}$ bond. The NHC-copper phosphides were found to be the most selective catalysts yet reported for the hydrophosphination of isocyanates. They provide access to a broad range of phosphinocarboxamides in excellent conversion and good yield.
\end{abstract}

The exploitation of metal phosphides is a widespread route to organophosphorus compounds. ${ }^{1-4}$ Beyond their stoichiometric application, catalytic intermediates of the form $\mathrm{L}_{n} \mathrm{MPR}_{2}$ have been integral to a green revolution in organophosphorus chemistry, especially when the metals concerned are Earthabundant first row transition metals (i.e., Fe, Co). These mid-dblock systems, however, are prone to redox-switching and single-electron transfer reactions which, coupled with the stability of phosphorus centred radicals, often result in undesirable side reactions. ${ }^{5-7}$

The propensity of copper(I) towards the well-defined isohypsic reaction steps of $\sigma$-bond metathesis, and insertion of unsaturated substrates should allow copper(I) phosphides to overcome such issues. Despite this appeal, copper phosphides often form only as complex oligomers, with a concomitant reduction in reactivity. ${ }^{8-17}$ Low-coordinate copper phosphides

\footnotetext{
${ }^{a}$ Department of Chemistry, University of Bath, Claverton Down, Bath, BA2 7AY, UK. E-mail:dl260@bath.ac.uk

${ }^{b} X$-Ray Crystallography Suite, University of Bath, Claverton Down, Bath, BA2 7AY, UK. E-mail:m.f.mahon@bath.ac.uk

$\dagger$ Electronic supplementary information (ESI) available: General synthetic experimental details, NMR spectra, X-ray analysis of compounds 1-7. DOSY experiments, details of the computational analysis and atomic coordinates of the DFT computed structures. CCDC 2014370-2014376. For ESI and crystallographic data in CIF or other electronic format see DOI: 10.1039/d0cc05694d
}

supported by sterically demanding ligands are far less common, as evidenced by the small number of structurally characterised $(\mathrm{NHC}) \mathrm{CuPR}_{2} \quad(\mathrm{NHC}=\mathrm{N}$-heterocyclic carbene) complexes hitherto reported. ${ }^{18}$ Despite their relative rarity, such species hint at the potential of low-molecularity copper(I) phosphides. For example, $\left[(\mathrm{NHC}) \mathrm{CuPPh}_{2}\right]_{3}$ complexes $\left(\mathrm{NHC}=\mathrm{I}^{\mathrm{i}} \mathrm{Pr}, 1,3\right.$-bis(isopropyl)-imidazol-2-ylidene; I $\mathrm{I}^{t} \mathrm{Bu}, 1,3-$ bis(tert-butyl)-imidazol-2-ylidene), mediate the hydrophosphination of terminal alkynes at elevated temperature. ${ }^{19}$

In contrast to the formation of alkyl and alkenyl phosphines from alkenes and alkynes, hydrophosphination of isocyanates has been far less well-studied. Often, significant competing side-reactivity ${ }^{6}$ or poor substrate scope ${ }^{20}$ hamper access to, and thus exploitation of, phosphinocarboxamide products. These products are potential synthetic intermediates and, particularly, ligands owing to their polydentate nature comprising both hard and soft donor atoms. ${ }^{21-23}$

Ring expanded N-heterocyclic carbenes (RE-NHCs) can offer increased stability and reduced molecularity to reactive metal species through their significant steric demand. ${ }^{24-26}$ RE-NHCcopper(I) complexes such as copper(I) halides and copper(I) alkoxides have been established as having enhanced catalytic activity over their five-membered ring counterparts. ${ }^{27-29}$

We thus set out to synthesise and characterise a range of low-coordinate copper phosphide species supported by both 5- and 6-membered NHCs in order to evaluate their potential as catalytic intermediates. Herein we report the rational synthesis of four $(\mathrm{NHC}) \mathrm{CuPPh}_{2}$ compounds (NHC = IPr, 6-Dipp, SIMes and 6-Mes), including the first examples of RE-NHC copper phosphides. These compounds were fully characterised by NMR spectroscopy and X-ray crystallography and investigated for their onward reactivity towards heterocumulenes. This access to well-defined putative reaction intermediates allows us to report the most selective catalytic hydrophosphination of isocyanates found to date.

Addition of 1 equivalent of $\mathrm{Ph}_{2} \mathrm{PSiMe}_{3}$ to a colourless benzene solution of (IPr) $\mathrm{CuO}^{t} \mathrm{Bu}$ resulted in the instantaneous 


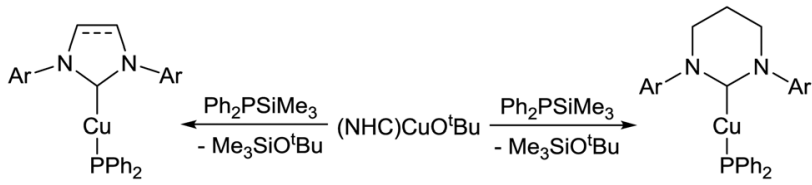

$1 \mathrm{Ar}=\operatorname{Dipp}(\mathrm{IPr})$

$3 \mathrm{Ar}=$ Mes (SIMes)

Scheme 1 Synthesis of (NHC)CuPPh

appearance of a yellow colouration and the emergence of new peaks in the ${ }^{1} \mathrm{H}$ and ${ }^{31} \mathrm{P}$ NMR spectra. (IPr) $\mathrm{CuPPh}_{2}, 1$, was isolated from this solution (Scheme 1) in $81 \%$ yield, and characterised by the presence of a ${ }^{31} \mathrm{P}\left\{{ }^{1} \mathrm{H}\right\}$ NMR resonance at $\delta-26.1 \mathrm{ppm}$, consistent with the data previously reported by Nolan and co-workers. ${ }^{30}$ Application of these conditions to $(\mathrm{NHC}) \mathrm{CuO}^{t} \mathrm{Bu}$ ( $\mathrm{NHC}=6$-Dipp, SIMes and 6-Mes) yielded (6-Dipp)CuPPh, 2 , as a yellow solid, as well as (SIMes)CuPPh, 3 , and (6-Mes) $\mathrm{CuPPh}_{2}, 4$, as orange solids (Scheme 1). Compounds 2, 3 and 4 each exhibit a single ${ }^{31} \mathrm{P}\left\{{ }^{1} \mathrm{H}\right\}$ NMR resonance at $\delta-23.8,-32.0$ and $-23.5 \mathrm{ppm}$ respectively. The presence of peaks attributed to ${ }^{t} \mathrm{BuOSiMe}_{3}$ in the ${ }^{1} \mathrm{H}$ NMR spectra of each of these reactions was interpreted as an indication that the formation of compounds 1-4 occurs via a $\mathrm{Cu}-\mathrm{O} / \mathrm{P}-\mathrm{Si} \sigma$-bond metathesis.

Crystals suitable for single crystal X-ray diffraction analysis of 1-4 were grown from benzene/hexane solutions at room temperature. Compounds 1 (Fig. S1, ESI $\dagger$ ) and 2 (Fig. 1a), featuring bulky diisopropylphenyl groups on the flank of the NHC, exhibit monomeric structures with a near-linear geometry at the copper centre (1: C1-Cu1-P1 177.09(6) ${ }^{\circ}$ 2: C1-Cu1-P1 177.51 $(6)^{\circ}$ ). Compounds 3 (Fig. 1b) and 4 (Fig. S2, ESI $\dagger$ ), containing less sterically-encumbering mesityl groups, adopt dimeric crystal structures in which the copper centres are threecoordinate, bonding to two bridging phosphorus atoms to give approximately rhomboid four-membered rings (3: P1-Cu1-P1 ${ }^{\mathrm{i}}$ 88.712(16) $)^{\circ}, \mathrm{Cu} 1-\mathrm{P} 1-\mathrm{Cu} 1^{\mathrm{i}}$ 91.286(16) ${ }^{\circ}$; 4: P1-Cu1-P2 85.61(3) ${ }^{\circ}$, $\left.\mathrm{Cu} 1-\mathrm{P} 2-\mathrm{Cu} 294.66(3)^{\circ}\right)$. Previous reports of dimeric NHCcopper(I) complexes supported by less bulky NHCs feature short $\mathrm{Cu} \cdot \mathrm{Cu}$ distances of $2.23-2.31 \AA$, which were interpreted as indicating the presence of copper-copper interactions. The longer $\mathrm{Cu} \cdots \mathrm{Cu}$ interatomic distances of compounds 3 (3.3502(7) ̊) and 4 (3.4852(5) ̊) suggest there is no significant interaction between the metal centres in these two cases. Comparatively, the only other structurally characterised $(\mathrm{NHC}) \mathrm{CuPPh}_{2},\left[\left(\mathrm{I}^{t} \mathrm{Bu}\right) \mathrm{CuPPh}_{2}\right]_{3}$, adopts a trimeric structure in the solid state. ${ }^{19}$

The $\mathrm{Cu}-\mathrm{C}_{\mathrm{NHC}}$ bond distances of compounds 1-4 range between 1.90-1.97 A. The monomeric complexes, 1

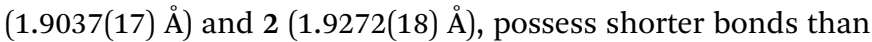
in 3 (1.9234(15) $⿱$ ) and 4 (1.969(3), 1.965(3) $\AA$ ), an observation attributed to the increased steric demand provided by two bridging phosphides. These compare with the even longer $\mathrm{Cu}-\mathrm{C}_{\mathrm{NHC}}$ bonds of 1.990-1.997 $\AA$ observed in trimeric [( $\left.{ }^{t} \mathrm{Bu}\right)$ $\left.\mathrm{CuPPh}_{2}\right]_{3} \cdot{ }^{19}$ Complexes 2 and $\mathbf{4}$, featuring ring-expanded NHCs, have noticeably longer $\mathrm{Cu}-\mathrm{C}_{\mathrm{NHC}}$ bonds than $\mathbf{1}$ and 3 respectively, likely due to the enhanced steric demand of the flanking aryl groups resulting from the increased $\mathrm{N}-\mathrm{C}-\mathrm{N}$ bond angle of the NHC. These trends are conserved in the $\mathrm{Cu}-\mathrm{P}$ bond (a)
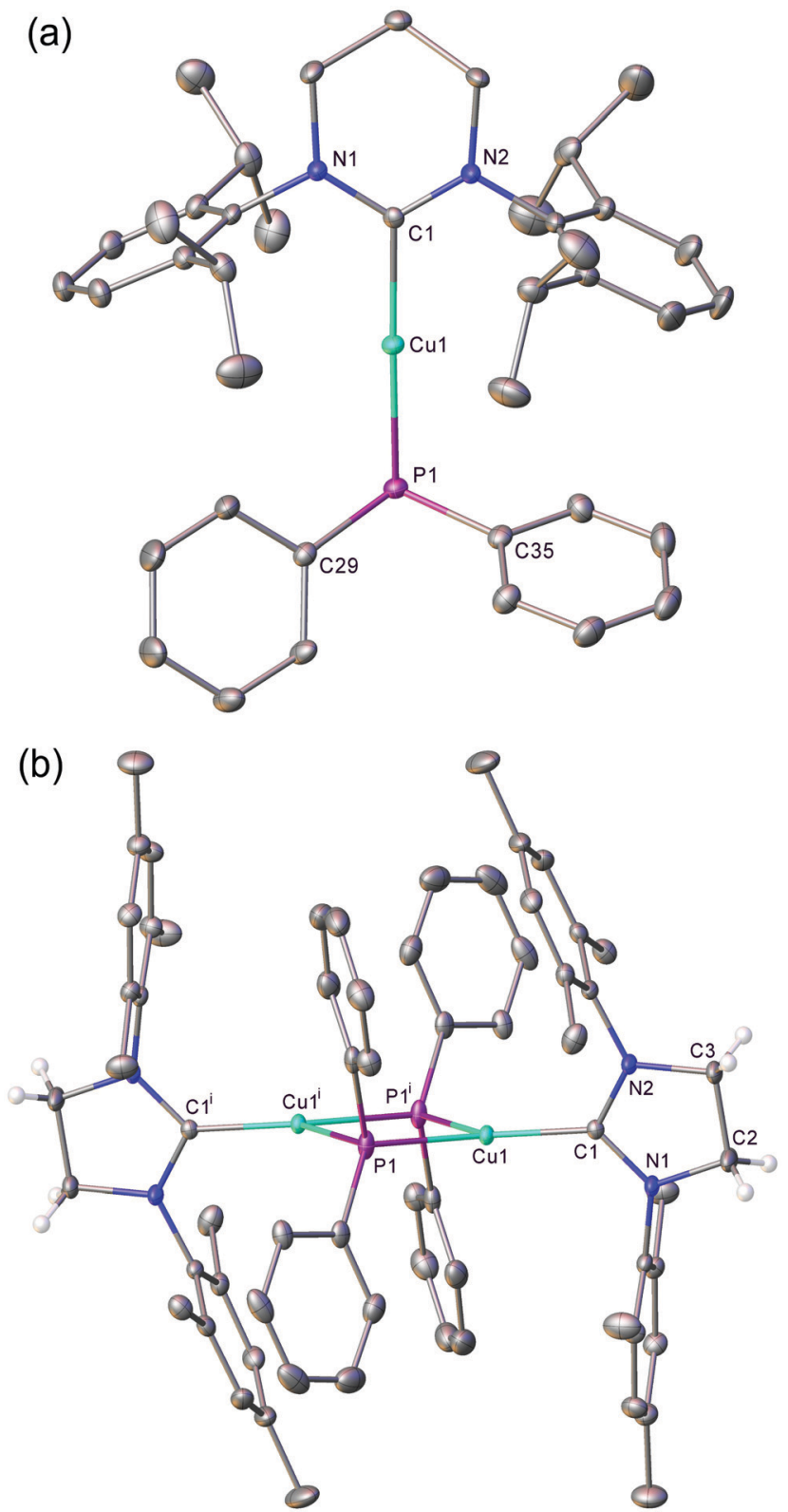

Fig. 1 ORTEP representations (30\% probability ellipsoids) of (a) compound 2 and (b) compound $\mathbf{3}$. Hydrogen atoms except those on the $\mathrm{NHC}$ backbone of $\mathbf{3}$ are omitted for clarity. Selected bond lengths $(\AA)$ and angles ( ${ }^{\circ}$ : (2) Cu1-P1 2.2113(5), Cu1-C1 1.9272(18), P1-C29 1.835(2), P1-C35 1.836(2), C1-Cu1-P1 177.51(6), Cu1-P1-C29 107.31(6), Cu1-P1-C35 102.92(6), C29-P1-C35 105.12(9); (3) Cu1-P1 2.3298(5), Cu-P1i 2.3558(5), Cu1-C1 1.9234(15), P1-C22 1.824(2), P1-C28 1.8208(18), C1-Cu1-P1 137.59(5), C1-Cu1-P1 133.14(4) P1-Cu1-P1 $1^{i}$ 88.712(16) Cu1-P1-Cu1 ${ }^{i}$ 91.286(16), Cu1-P1-C22 110.55(5), Cu1-P1-C28 121.30(6).

distances which are longer for the RE-NHC containing compounds, 2 and 4, compared to their respective 5-membered

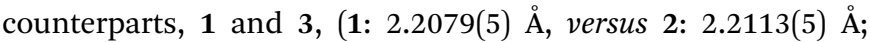
$32.3298(5) \AA$, versus 4 2.3803(9), 2.3908(8) §) and wherein the dimeric species 3 and 4 show greater $\mathrm{Cu}-\mathrm{P}$ distances than the monomeric compounds, 1 and 2.

In order to investigate the persistence of the observed solidstate structures in solution, the compounds were interrogated 
by diffusion ordered ${ }^{1} \mathrm{H}$ NMR spectroscopy (DOSY). Compounds 1 and 2 were found to have hydrodynamic radii that corresponded to their crystallographically derived monomeric structures (1: $r_{\text {DOSY }}=5.40 \AA, r_{\text {comp }}=5.31 \AA ; 2: r_{\text {DOSY }}=5.27 \AA$, $r_{\text {comp }}=5.52 \AA$ ). The hydrodynamic radius observed by DOSY for compound 3 showed a close correlation with that calculated for its dimeric structure seen in the solid state $\left(3: r_{\text {DOSY }}=6.03 \AA\right.$, $r_{\text {comp }}=6.50 \AA$ ). This interpretation is corroborated by the lowtemperature $(235 \mathrm{~K}){ }^{13} \mathrm{C}\left\{{ }^{1} \mathrm{H}\right\}$ NMR spectrum of 3 which shows a broad triplet for the carbenic carbon from a ${ }^{2} J^{13} \mathrm{C}_{-31} \mathrm{P}$ coupling to the two bridging but equivalent phosphorus atoms. Compound 4, however, was found to have a hydrodynamic radius that was more consistent with it existing in solution as a monomer, not the dimer observed in the solid state $\left(4: r_{\mathrm{DOSY}}=5.29 \AA\right.$, $r_{\text {comp }}=5.21 \AA$ for monomer, $r_{\text {comp }}=6.55 \AA$ for dimer $)$.

Addition of a slight excess of isopropyl isocyanate to a yellow $\mathrm{C}_{6} \mathrm{D}_{6}$ solution of 2 resulted in a loss of colour. Analysis by ${ }^{31} \mathrm{P}\left\{{ }^{1} \mathrm{H}\right\}$ NMR spectroscopy revealed the attenuation of the resonance assigned to 2 , and the appearance of a single major resonance at $\delta 2.2 \mathrm{ppm}$. Comparison to the ${ }^{31} \mathrm{P}\left\{{ }^{1} \mathrm{H}\right\} \mathrm{NMR}$ signal of $\delta-4.0 \mathrm{ppm}$ observed for the free phosphaurea $\mathrm{Ph}_{2} \mathrm{PC}(\mathrm{O}) \mathrm{NH}\left({ }^{\mathrm{i}} \mathrm{Pr}\right)$ was interpreted as implying that insertion of the isocyanate into the $\mathrm{Cu}-\mathrm{P}$ bond had occurred (Scheme 2). ${ }^{6}$ The corresponding ${ }^{1} \mathrm{H}$ NMR spectrum exhibited a new set of peaks consistent with a complex incorporating the 6-Dipp ligand and the isopropyl isocyanate.

The formation of (6-Dipp) $\mathrm{Cu}\left[\mathrm{N}\left({ }^{\mathrm{i}} \mathrm{Pr}\right) \mathrm{C}(\mathrm{O}) \mathrm{PPh}_{2}\right]$, 5, was confirmed by X-ray diffraction analysis, performed on colourless single crystals which grew from the reaction solution when left to stand at room temperature (Fig. 2). In contrast to previously reported phosphaureates which comprise a $\kappa^{2}-(\mathrm{N}, \mathrm{O})$ coordination mode and delocalised $\pi$-bonding, ${ }^{21-23} 5$ features $\kappa^{1}$-coordination of the nitrogen to the copper atom. This results in a relatively short $\mathrm{Cu}-\mathrm{N}$ bond length (1.9053(11) $\mathrm{A})$, with $\mathrm{C}-\mathrm{N}$ (1.3314(19) ̊) and $\mathrm{C}=\mathrm{O}(1.2383(17) \AA$ ) bond lengths consistent with localised single and double bonds respectively. Evidence for the persistence of this bonding mode in solution can be inferred from the ${ }^{31} \mathrm{P}\left\{{ }^{1} \mathrm{H}\right\}$ NMR signal at $2.2 \mathrm{ppm}$. This value is significantly downfield of known $\mathrm{Zr}$ (IV) and $\mathrm{Y}$ (III) compounds which feature a delocalised $\kappa^{2}-(\mathrm{N}, \mathrm{O})$ bonding mode in the solid state and solution ${ }^{31} \mathrm{P}\left\{{ }^{1} \mathrm{H}\right\}$ NMR spectra containing resonances at $\delta-12.1$ and $-20.1 \mathrm{ppm}$ respectively. ${ }^{21,22}$

The facile insertion of an isocyanate into the $\mathrm{Cu}-\mathrm{P}$ bond of 2 prompted a study of other electrophiles. Reactions with excesses of phenyl isothiocyanate and carbon disulfide resulted in insertion of the respective heterocumulene into the $\mathrm{Cu}-\mathrm{P}$ bond to give new compounds, 6 and 7 (Scheme 2). X-Ray diffraction

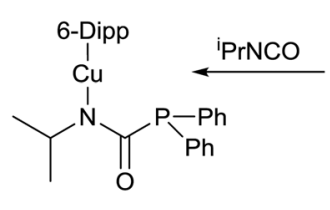

5

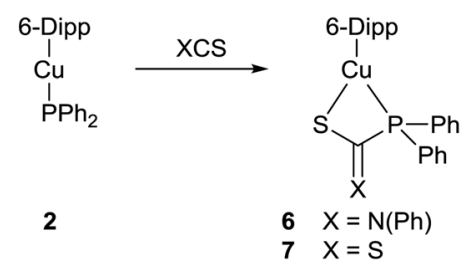

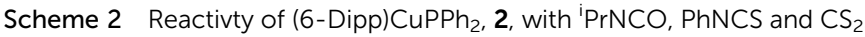

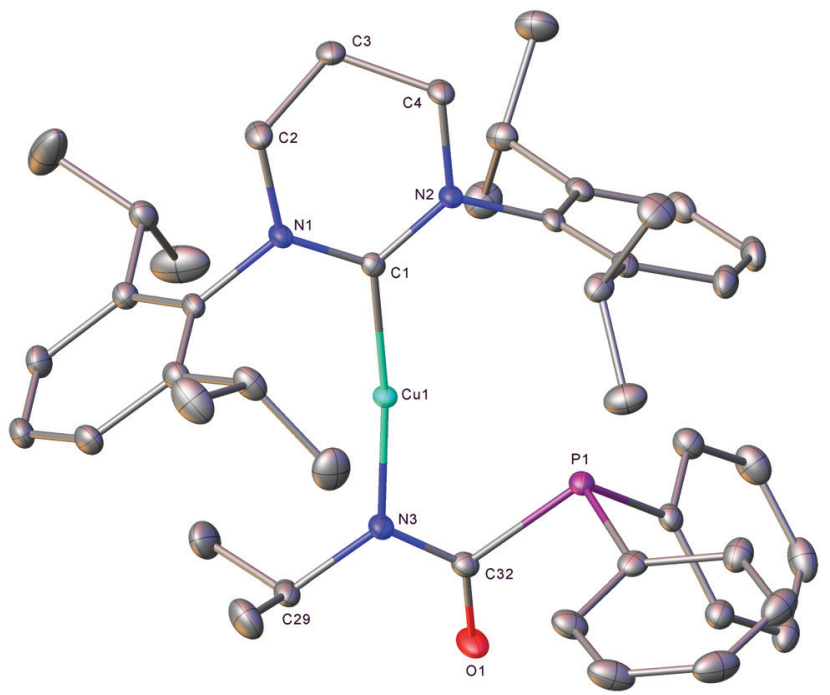

Fig. 2 ORTEP representations (30\% probability ellipsoids) of compound $\mathbf{5}$. Hydrogen atoms are omitted for clarity. Selected bond lengths $(\AA \AA)$ and angles $\left({ }^{\circ}\right)$ : Cu1-N3 1.9053(11), Cu1-C1 1.9283(13), N3-C29 1.4871(18), N3-C32 1.3314(19), O1-C32 1.2383(17), P1-C32 1.8826(14), C1-Cu1-N3 173.90(5), Cu1-N3-C29 124.19(9), Cu1-N3-C32 120.92(9), N3-C32-O1 128.34(13), N3-C32-P1 109.84(9), O1-C32-P1 121.76(11).

analysis performed on colourless crystals of 6 (Fig. S3, ESI $\dagger$ ) and red crystals of 7 (Fig. S4, ESI $\dagger$ ) reveal that the copper centre is bonded to the sulfur atom in both cases. In contrast to the phosphaureate 5 , the phosphorus atoms in compounds 6 and 7 also coordinate to the metal centre resulting in CuSCP fourmembered rings in both cases. The ${ }^{31} \mathrm{P}\left\{{ }^{1} \mathrm{H}\right\}$ NMR spectra of 6 and 7 each reveal a single major resonance, at $\delta 28.8$ and $45.2 \mathrm{ppm}$ respectively.

Addition of 1 equivalent of diphenylphosphine to a colourless solution of compound $\mathbf{5}$ resulted immediately in yellow colouration, and inspection of the ${ }^{31} \mathrm{P}\left\{{ }^{1} \mathrm{H}\right\}$ NMR spectrum suggested that $\mathrm{Ph}_{2} \mathrm{PC}(\mathrm{O}) \mathrm{NH}\left({ }^{\mathrm{i}} \mathrm{Pr}\right)$ had been liberated with the regeneration of complex 2. These stoichiometric reactions could be assembled into a catalytic manifold (Fig. 3) to hydrophosphinate a range of isocyanates with diphenylphosphine in $\mathrm{C}_{6} \mathrm{D}_{6}$ in the presence of $1 \mathrm{~mol} \%$ of 1-4 (Table 1 ).

Whilst catalyst-free hydrophosphination of isocyanates can be conducted under strictly neat conditions, the reactivity was limited to a range of small aromatic isocyanates $;^{20}$ cyclohexyl

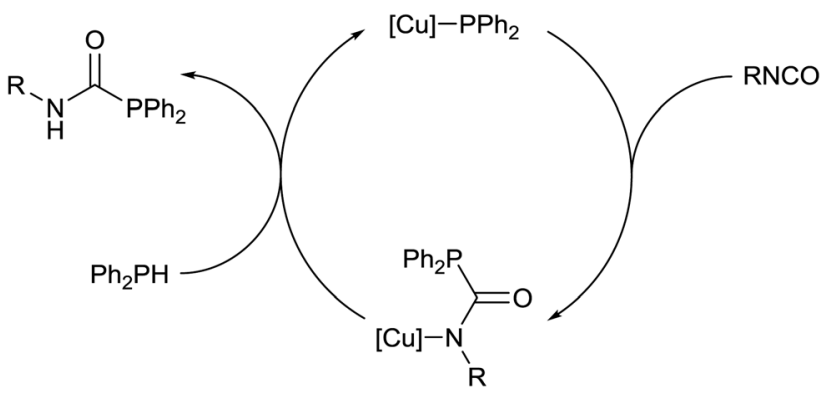

Fig. 3 Proposed mechanism for the copper-catalysed hydrophosphination of isocyanates. 
Table 1 Catalytic hydrophosphination of isocyanates $(0.20 \mathrm{mmol})$ with $\mathrm{Ph}_{2} \mathrm{PH}(35 \mu \mathrm{L}, 0.20 \mathrm{mmol})$ and $1 \mathrm{~mol} \% 1-4$ in $\mathrm{C}_{6} \mathrm{D}_{6}(0.5 \mathrm{~mL})$

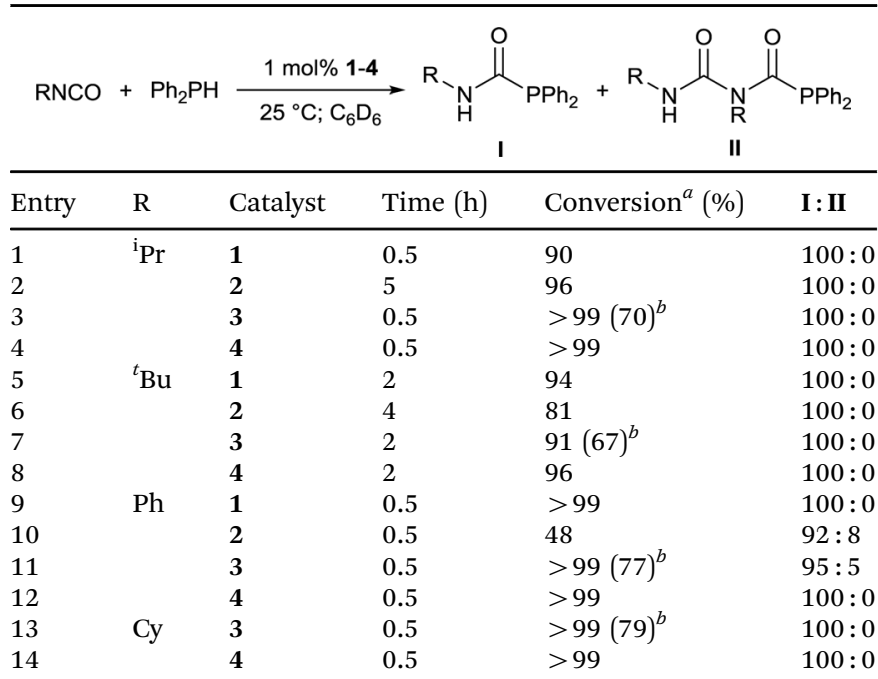

${ }^{a}$ Conversions based on relative ${ }^{1} \mathrm{H}$ and ${ }^{31} \mathrm{P}$ NMR spectroscopic integrations of starting material and product. ${ }^{b}$ Isolated yields of $\mathbf{I}$ from a preparative scale reaction in toluene, see ESI.

isocyanate exhibited no reactivity under such conditions. In contrast, 1 mol\% of complexes 3 and $\mathbf{4}$ brought about full conversion of both cyclohexyl and isopropyl isocyanate within 30 minutes, and even the very sterically-congested tert-butyl isocyanate reached excellent conversions ( $>90 \%$ ) within 2 hours. 2 was found to catalyse the reaction more slowly than $\mathbf{1}, \mathbf{3}$, and $\mathbf{4}$, attributable to the greater steric demands of the 6-Dipp ligand.

In contrast to the iron-catalysed hydrophosphination of isocyanates, ${ }^{6}$ only very limited amounts of double insertion of the $\mathrm{N}=\mathrm{C}$ bond were observed for phenyl isocyanate when catalysed by 2 or 3 , and none was observed when 1 or 4 were the precatalyst. In all other cases, the reaction was specific for single insertion, and in no case was the formation of $\mathrm{Ph}_{2} \mathrm{PPPh}_{2}$ observed.

In conclusion, the synthesis of a series of NHC-copper(I) phosphides was accomplished by reaction of alkoxide precursors with $\mathrm{Ph}_{2} \mathrm{PSiMe}_{3}$. Complexes 1-4, including the first reports of RENHC copper(I) phosphides (compounds 2 and 4), were found to be either monomeric or dimeric in the solid- and solution-state depending on the steric bulk of the NHC ligand. Reaction of 2 with isocyanates, isothiocyanates and carbon disulfide resulted in the insertion of the heterocumulene into the $\mathrm{Cu}-\mathrm{P}$ bond to give compounds 5-7. Compounds 1-4 were found to be highly active and selective precatalysts for the hydrophosphination of isocyanates. We continue to investigate the nature and scope of this catalytic reactivity, including its application in the hydrophosphination of other heterocumulenes.

This research made use of the Balena High Performance Computing (HPC) Service at the University of Bath. DJL thanks the Royal Society for the support of a University Research
Fellowship. We acknowledge financial support from the EPSRC Centre for Doctoral Training in Catalysis (EP/L016443/1) for JWH.

\section{Conflicts of interest}

There are no conflicts to declare.

\section{Notes and references}

1 S. Greenberg and D. W. Stephan, Chem. Soc. Rev., 2008, 37, 1482-1489.

2 L. Rosenberg, ACS Catal., 2013, 3, 2845-2855.

3 V. Koshti, S. Gaikwad and S. H. Chikkali, Coord. Chem. Rev., 2014, 265, 52-73.

4 D. S. Glueck, J. Org. Chem., 2020, DOI: 10.1021/acs.joc.0c00667.

5 A. K. King, A. Buchard, M. F. Mahon and R. L. Webster, Chem. - Eur. J., 2015, 21, 15960-15963.

6 H. R. Sharpe, A. M. Geer, W. Lewis, A. J. Blake and D. L. Kays, Angew. Chem., Int. Ed., 2017, 56, 4845-4848.

7 J. Rajpurohit, P. Kumar, P. Shukla, M. Shanmugam and M. Shanmugam, Organometallics, 2018, 37, 2297-2304.

8 T. Greiser and E. Weiss, Chem. Ber., 1978, 111, 516-522.

9 G. van Koten, J. G. Noltes and A. L. Spek, J. Organomet. Chem., 1978, 159, 441-463.

10 T. A. Annan, R. Kumar and D. G. Tuck, J. Chem. Soc., Chem. Commun., 1988, 446-448.

11 A. H. Cowley, D. M. Giolando, R. A. Jones, C. M. Nunn and J. M. Power, J. Chem. Soc., Chem. Commun., 1988, 208-209.

12 D. J. Brauer, G. Hessler, P. C. Knueppel and O. Stelzer, Inorg. Chem., 1990, 29, 2370-2375.

13 T. A. Annan, R. Kumar and D. G. Tuck, J. Chem. Soc., Dalton Trans., 1991, 11-18.

14 A. Eichhöfer, D. Fenske and W. Holstein, Angew. Chem., Int. Ed. Engl., 1993, 32, 242-245.

15 C. Meyer, H. Grützmacher and H. Pritzkow, Angew. Chem., Int. Ed. Engl., 1997, 36, 2471-2473.

16 S. Scholz, M. Bolte, M. Wagner and H.-W. Lerner, Z. Anorg. Allg. Chem., 2007, 633, 1199-1204.

17 P. J. Harford, J. Haywood, M. R. Smith, B. N. Bhawal, P. R. Raithby, M. Uchiyama and A. E. H. Wheatley, Dalton Trans., 2012, 41, 6148-6154.

18 B. Khalili Najafabadi and J. F. Corrigan, Dalton Trans., 2015, 44, 14235-14241.

19 J. Yuan, L. Zhu, J. Zhang, J. Li and C. Cui, Organometallics, 2017, 36, 455-459.

20 M. Itazaki, T. Matsutani, T. Nochida, T. Moriuchi and H. Nakazawa, Chem. Commun., 2020, 56, 443-445.

21 A. J. Roering, S. E. Leshinski, S. M. Chan, T. Shalumova, S. N. MacMillan, J. M. Tanski and R. Waterman, Organometallics, 2010, 29, 2557-2565.

22 W. Yi, J. Zhang, L. Hong, Z. Chen and X. Zhou, Organometallics, 2011, 30, 5809-5814.

23 R. J. Schwamm, J. R. Fulton, M. P. Coles and C. M. Fitchett, Dalton Trans., 2017, 46, 2068-2071.

24 J. Li, W.-X. Shen and X.-R. Li, Curr. Org. Chem., 2012, 16, 2879-2891.

25 M. J. Page, W. Y. Lu, R. C. Poulten, E. Carter, A. G. Algarra, B. M. Kariuki, S. A. Macgregor, M. F. Mahon, K. J. Cavell, D. M. Murphy and M. K. Whittlesey, Chem. - Eur. J., 2013, 19, 2158-2167.

26 R. C. Poulten, M. J. Page, A. G. Algarra, J. J. Le Roy, I. López, E. Carter, A. Llobet, S. A. Macgregor, M. F. Mahon, D. M. Murphy, M. Murugesu and M. K. Whittlesey, J. Am. Chem. Soc., 2013, 135, 13640-13643.

27 J. K. Park, H. H. Lackey, B. A. Ondrusek and D. T. McQuade, J. Am. Chem. Soc., 2011, 133, 2410-2413.

28 J. W. Hall, D. M. L. Unson, P. Brunel, L. R. Collins, M. K. Cybulski, M. F. Mahon and M. K. Whittlesey, Organometallics, 2018, 37, 3102-3110.

29 F. Sebest, J. J. Dunsford, M. Adams, J. Pivot, P. D. Newman and S. Díez-González, ChemCatChem, 2018, 10, 2041-2045.

30 G. C. Fortman, A. M. Z. Slawin and S. P. Nolan, Organometallics, 2010, 29, 3966-3972. 